\title{
Occupational status, working conditions, and health: evidence from the 2012 China Labor Force Dynamics Survey
}

\author{
Yaqiang $\mathrm{Qi}{ }^{i^{*}} \mathbb{D}$, Tongxin Liang ${ }^{2}$ and Hua Ye $\mathrm{S}^{3^{*}}$
}

\author{
*Correspondence: qiyaqiang@ruc. \\ edu.cn; yehua5@mail.sysu.edu.cn \\ ${ }^{1}$ Department of Sociology, Renmin \\ University of China, No.59 \\ Zhongguancun Street, Haidian \\ District, Beijing 100872, China \\ ${ }^{3}$ School of Sociology and \\ Anthropology, Sun Yat-Sen \\ University, Guangzhou, China \\ Full list of author information is \\ available at the end of the article
}

\begin{abstract}
This study investigates the relationship between occupational status and health inequality in the working population by analyzing data from the 2012 China Labor Force Dynamics Survey. The results show that individual health varies substantially by occupational status, including self-assessed health, work-related injury, and self-reported occupational disease. Low occupational status is associated with poorer self-assessed health and increased incidences of work-related injuries, while people with the high occupational status report more occupational diseases. Further analysis indicates that working condition is the main mediator between occupational status and individual health. Based on the results from the Karlson-Holm-Breen decomposition, the disparities in working conditions, including working overtime, environmental and occupational hazards, job demand and control, and perceived rewards, account for approximately half of the effects of occupation status on individual health.
\end{abstract}

Keywords: Occupation, Working condition, Health inequality, Effect decomposition

\section{Springer Open}

\section{Introduction}

As an intrinsic part of human well-being, health is of great significance to the quality of an individual's life and the overall development of society. Since the 1970s, health inequality has become an important topic for studies of social stratification. Increasingly more scholars are interested in how social structure and stratification affect the health of different social groups through mechanisms, such as risk management and resource allocation. As the core of the modern social stratification system, occupation is also included in this endeavor.

Researchers found that substantive health disparities exist between different occupational groups. These differences have not been narrowed down with the advancement of medical technology, social and economic development, and even the establishment of a universal health care system. Therefore, the relationship between occupation and health remains a vital public concern that calls for further investigation.

Occupational health affects not only the well-being of workers and their families but also the sustainability of social and economic development. It is estimated that the

(c) The Author(s). 2020 Open Access This article is licensed under a Creative Commons Attribution 4.0 International License, which permits use, sharing, adaptation, distribution and reproduction in any medium or format, as long as you give appropriate credit to the original author(s) and the source, provide a link to the Creative Commons licence, and indicate if changes were made. The images or other third party material in this article are included in the article's Creative Commons licence, unless indicated otherwise in a credit line to the material. If material is not included in the article's Creative Commons licence and your intended use is not permitted by statutory regulation or exceeds the permitted use, you will need to obtain permission directly from the copyright holder. To view a copy of this licence, visit http://creativecommons.org/licenses/by/4.0/. 
economic losses caused by occupational health problems can represent up to $14 \%$ of the gross national product (Leigh et al. 1999). As a developing country with a huge working-age population, China faces more prominent occupational health problems than those of other countries. Since the beginning of market-oriented reform, China has become increasingly and deeply integrated into the world system of division of labor, relying on its relative advantages in land and labor to become the "world factory." Rapid economic growth has not only improved the overall quality of life and life expectancy of the Chinese population but also led to increasing challenges for occupational safety and health. According to official statistics, a total of 29,789 cases of occupational diseases were reported nationwide in 2011, including 26,401 cases of pneumoconiosis and 1829 cases of acute and chronic occupational poisoning. ${ }^{1}$ In the same year, a total of 347,728 production accidents occurred throughout the country, resulting in 75,572 deaths. ${ }^{2}$ Taking into account possible underreporting, the real situation may be even more severe than that reflected by the above statistical data.

Compared to many Western societies, previous studies on the relationship between occupation and health are relatively rare in China. Existing evidence is mostly drawn from small-scale epidemiological investigations, which typically focus on certain specific workers or occupational diseases and therefore lack a holistic perspective of social stratification. In the field of sociology, although a few studies focus on the relationship between socioeconomic status and health, these studies only regard occupation as one of the indicators of social stratification. Few studies have examined the specific mechanisms by which occupational status affects individual health.

In this study, we use data from the 2012 China Labor Force Dynamics Survey to examine differences in health status and working conditions among different occupations in China, paying special attention to how occupation affects individual health through a series of specific working conditions, including workload and working environment, job demand and control, job rewards, and other mechanisms. Our study aims to gain a deeper understanding of China's social stratification and its health consequences during its rapid social transformation and provide new insights for improving the health of Chinese workers, reducing health inequalities, and promoting sustainable social and economic development.

\section{Literature review and research hypothesis}

Occupational stratification and health inequality

Sociological studies of health argue that the health status of individuals is not a simple personal problem but is profoundly affected by the macro-social structure. In fact, health is one of the primary elements of "life chances" described by Max Weber, and health inequality reflects how social structure restricts the living space of different social groups through the unequal allocation of vital resources and subsequently induces profound consequences to individual health.

\footnotetext{
${ }^{1}$ For details, please refer to the website of the Disease Prevention and Control Bureau of the National Health and Family Planning Commission of China, "Notice on the Prevention and Control of Occupational Diseases in 2011" (http: //www.nhfpc.gov.cn/jkj/s5899t/201130/14ddbd8fcd7b4385a1d0a6353b5cebf.shtml).

${ }^{2}$ For details, please refer to the website of the State Administration of Work Safety Supervision and Administration, "The state of national safety production in 2011" (http://www.chinasafty.gov.cn/newpage/ Contents/Chanel_4181/2012/0114/16712/content_2016712.htm).
} 
From this perspective, many studies have examined the relationship between social class and health. Among these studies, occupation is undoubtedly the bedrock for class differentiation in modern societies. On the one hand, occupation serves as a bridge connecting education and income and is the main channel for the distribution of life chances and material resources between different social groups. On the other hand, occupation is the main source of social prestige and political power, and the nature of the job engaged by an individual determines his/her reputation and status in society. Studies have shown that a gradient in health exists based on occupational status. People with higher occupational status tend to enjoy better health and lower mortality, and this gradient persists and even increases over time (Adler and Ostrove 1999; Marmot 2004; Winkleby et al. 1992). The differences in the nature of work and resultant working conditions may constitute an important reason for this health differentiation.

Along this line, early research focused more on the impact of work intensity and physical environment. Among them, the workload caused by long working hours and overtime work is one of the focuses of related discussions. Many studies have examined medical staff, white-collar workers, and countries with a tradition of long working hours (such as Japan) and found that long working hours and sleep deprivation are strongly associated with the occurrence of acute heart disease and "overwork death" (Leonard et al. 1998; Sokejima and Kagamimori 1998). If an individual does not have enough time to recover and rest his body from long-period and high-load work, the physiological processes of life will be disrupted, which subsequently causes damage to physical and mental health.

The safety of the working environment, especially exposure to the inhalation of harmful substances during the production process, is also an important cause of occupational diseases. With the advancement of industrialization, various types of chemicals are introduced into the processes of factory production. Exposure to these dangerous substances and inhalation of smoke and dust at the workplace will increase the risk of respiratory disease and cancer and pose a serious threat to the health of workers (Schrijvers and van de Mheen 1998; Zhang et al. 2010).

In addition, the psychosocial mechanism of occupational health has always been one of the main focuses of the sociology of health. A large body of literature in this area is inspired by the "job demand-control" model. The model claims that high intensity of workload and conflicts (i.e., job demand) will have a harmful impact on worker's health, while personal job control (i.e., the authority and autonomy to respond to these demands) can be used as a buffering mechanism to reduce those negative effects. When high demand and low control intersect, the resulting job strain will cause the most damage to health (Karasek 1979; Theorell et al. 1998). The "job demand-control" model provides an important theoretical framework for exploring the relationship between occupation and health, but the interaction between job demand and control has not been verified in all empirical investigations.

Instead, many studies have attempted to use job demand and job control as independent dimensions to examine their impacts on health. Among them, studies on job control generally show that people with a higher social class have greater autonomy in their work and life. Job control helps to reduce negative emotions, such as anxiety and stress, resulting in better work performance and life experience, effectively reducing the risk of heart disease and subsequent death (Marmot et al. 1997). In contrast, the effect 
of job demand on health is more complex. Some studies note that job demand does not necessarily bring high pressure and bad health, and moderate job demand may have a certain protective effect on health. Moreover, different types of job demands are likely to have different health consequences (Kristensen 1995; Kristensen et al. 2002).

The "job demand-control" model puts overwhelming emphasis on the working process itself and thus neglects inequalities in rewards brought about by different occupations. With the process of globalization and deindustrialization in developed countries, the mechanism by which occupation impacts health has far exceeded the production field. From the principle of reciprocity emphasized by social exchange theory, Siegrist and colleagues (Siegrist 1996; Siegrist and Wahrendorf 2016) propose the "effort-reward imbalance" model to explain the continuing impact of occupation on health. This theory holds that work is the most important social exchange activity in modern social life. On the one hand, high-intensity and overtime work, a dangerous working environment, and work-related stress constitute the daily experience of many workers at the bottom of social strata, and these efforts will wear down their bodies and lead to elevated risks of morbidity and mortality. On the other hand, jobs with low occupational status provide workers with few rewards, including lower material rewards, poorer job security, fewer opportunities for promotion, lower social prestige, and the lack of self-fulfillment. This imbalance between the effort and reward undermines the basic requirement of a person for the equivalence of social exchanges. It seriously impairs self-esteem and moral emotions and thus leads to physical and mental health problems. Subsequent empirical research shows that both the "job demandcontrol" model and the "effort-reward imbalance" model have strong explanatory powers and jointly reflect the complex mechanisms by which occupational status can act on worker's health (Siegrist and Wahrendorf 2016; Yu et al. 2013).

In short, the impact of occupation on individual health is realized through multiple pathways, including physical overloading, occupational safety, long-term stress, and psychosocial imbalances. These effects can essentially be regarded as the differential distribution of health-related risks and resources by occupational status through a series of specific working conditions. Therefore, investigations on the relationship between occupation and health should not be limited to the health problems of specific groups and certain workplaces but be carried out from a broad perspective of social stratification and health inequality.

\section{The challenges of occupational health in the world factory}

Compared with developed countries, research on the relationship between occupation and health has received relatively little attention in developing countries, including China. Indeed, due to low-level living standards and the lack of adequate occupational safety regulations, the occupational health problems encountered by these regions are more severe.

Since the economic globalization and the formation of the global division of labor began in the mid-twentieth century, many high-risk and low-end traditional industries have been shifted from developed to developing countries. This shift has brought profound changes to the socioeconomic structure of developing countries while also exacerbating dangers to the occupational health of workers. The working environment 
and safety conditions in developing countries are often poor, and relevant regulation systems for workers' rights and interests are not adequate. Therefore, workers face elevated risks of health threats (LaDou 2003; Liu et al. 2011).

Since the 1980s, along with market-oriented reforms, China has become increasingly involved in the global division of labor in the wave of economic globalization. As a "late developing" country, China was at a clear disadvantage in the international economic order. Restricted by capital and technological shortages, China relied on the relative advantages of cheap labor to develop its labor-intensive industries, such as product processing and manufacturing. This development model brought not only rapid economic growth but also a severe loss of labor health. The use of cheap labor has exposed a considerable number of workers to overtime and excessive work. In addition, the lack of a safe working environment has also caused them to face a series of health hazards at the workplace, such as dust inhalation, harmful chemical exposure, work-related injuries, and occupational diseases (Zhang et al. 2010).

The complex changes within Chinese society since the reform of the economic system have exacerbated occupational safety issues to some extent. The rapid economic growth and the transformation of ownership structure have led to the emergence of a large number of foreign-invested enterprises and small private enterprises. Compared with the state-owned sector, workers in these new establishments are often more difficult to be secured in terms of the working environment, production safety, and medical benefits (Chen and Chan 2010; Wang 2005). In some areas, the disorderly development of township enterprises and family workshops, together with the lack of occupational safety awareness and the outdatedness of technological equipment, has caused local workers to bear higher health risks (Su et al. 2000; Zhang et al. 2010). It can be said that China's current occupational health problems are manifested as a joint force from the "outside" and the "inside," including both the influence of the global division of labor on China's late development and the effect of a series of internal transformations in Chinese society.

As mentioned, empirical research on occupation and health problems in China remains severely insufficient, and glaring gaps are noted in the existing literature. Most existing studies take an epidemiological perspective, focusing on a certain occupational group and investigating the impact of specific working conditions on worker's health, such as the workload, working environment, and occupational pressure, and health consequences of specific factories (Qiao et al. 1997; Yu et al. 2008, 2012). These studies provide useful insights for exploring specific pathways in which occupation plays a role in health. However, due to the lack of a holistic perspective, it is impossible to obtain a panoramic picture of the working status and health among different occupations in China. These epidemiological studies are generally limited to specific occupational hazards for specific jobs, thus ignoring the forces of social stratification behind the surface.

There are also sociological studies that are concerned about China's social stratification and health inequality. For instance, many studies have examined the effects of education, income, and occupation on self-assessed health (Chen et al. 2010; Hu 2014; Jiao 2014; Qi 2006). Although some of these studies touch on occupation (Jiao 2014; Qi 2006), it is only used as one of the indicators to measure the socioeconomic status, and none of these studies focus on the specific mechanisms through which occupational status affects health. 
Since China's market-oriented reforms and the subsequent transformation of social stratification and mobility, the social structure has gradually been diversified, and occupation has increasingly become the basis of class differentiation in contemporary China (Li et al. 2012). Especially in the process of transition from a planned economy to a market economy, different ownership structures have coevolved in parallel, and the institutional division based on the nature of the work unit has added a distinctive layer to China's occupational differentiation (Li 2007; Li et al. 2009). Therefore, a systematic examination of health disparity between different occupational groups and its underlying mechanism has important theoretical and practical significance for understanding the current social structure differentiation and health inequality in China.

To fill the gap in the literature, this study uses a national dataset of China's labor force to compare the health and working conditions of different occupational groups and to test specific mechanisms through which occupation affects worker's health. This study aims to provide a new empirical basis for comprehensively understanding the health consequences of social differentiation in transitioning China to improve the health of Chinese workers effectively.

\section{Research hypothesis}

This study addresses the following questions: (1) What is the difference in health status and working conditions across different occupational groups in Chinese society? (2) How does occupation affect people's health through various specific working conditions? Based on the discussion of existing literature, we mainly explore the mediating effects of working conditions from four aspects: working hours, working environment, job demand and control, and occupational security and rewards.

Research on health inequality suggests that social stratification makes a significant difference in individual health through a series of unequal distributions of life opportunities and social resources (Adler and Ostrove 1999). As the core of modern social stratification and the main resource allocation mechanism, the occupation has an important impact on the health of workers. Thus, we propose the following hypothesis.

Hypothesis 1: Workers with different occupational status exhibit significant differences in health status. The higher the occupational status, the better the health.

Studies of Chinese social stratification indicate that the work unit still plays a vital role in social differentiation and resource allocation ( $\mathrm{Li} \mathrm{2007;} \mathrm{Li} \mathrm{et} \mathrm{al.} \mathrm{2009).} \mathrm{State-}$ owned enterprises provide their employees with a complete health care system, which is far superior to private enterprises with respect to production safety facilities and medical security services (Chen and Chan 2010; Su et al. 2000). When discussing the relationship between occupation and health in Chinese society, it is necessary to take into account the influence of the work unit. Accordingly, we propose the following hypothesis.

Hypothesis 2: The effect of occupation on worker's health is moderated by the nature of the work unit. Compared with other units, the health status of employees in state-owned and collective units is less affected by occupational status. 
Previous studies have reported that differences in a range of working conditions, including working hours, working environment, job demand and control, and effort and rewards, represent different levels of risks and resources for health, which constitute an important reason for the health differentiation by occupation (Landsbergis 2010; Schrijvers and van de Mheen 1998). Therefore, we propose the following hypothesis.

Hypothesis 3: The impact of occupational status on individual health is largely based on working conditions.

Moreover, we further explore the specific pathways by which working conditions affect health. Long working hours and overloaded work will lead to stress and fatigue, causing a series of adverse health consequences (Leonard et al. 1998; Liu et al. 2011). Accordingly, we put forward the following hypothesis for overtime work.

Hypothesis 3.1: Overtime work is an important mechanism by which occupation affects health. The longer an individual works overtime, the worse his health.

At the workplace and in production processes, inhalation of dust, exposure to radioactive and chemical substances, and other occupational hazards will expose workers to many deadly diseases, including cancer, posing a serious threat to their health (Schrijvers and van de Mheen 1998: Zhang et al. 2010). Thus, we propose the following hypothesis for the working environment and occupational hazards.

Hypothesis 3.2: Workplace safety is an important mechanism by which occupation affects health. Exposure to harmful substances at the workplace and the lack of necessary protective measures will have a negative impact on individual health.

The "job demand-control" model claims that high job demand damages physical and mental health through psychosocial mechanisms, and job control formed by organizational authority and autonomy can be used as a "buffering" mechanism to alleviate the harmful effect of job demand on health (Karasek 1979; Theorell et al. 1998). Therefore, we propose the following hypothesis for job demand and control.

Hypothesis 3.3: Job demand and job control are important mechanisms by which occupation affects health. The higher the demand individuals face at work and the lower the degree of control over the job, the worse their health.

According to the "effort-reward imbalance" theory, the difference in occupational reward is also an important dimension that affects the health of workers. Among them, medical insurance is a key factor to ensure that people can enjoy good health care (Andersen and Newman 2005). Inequalities in access to medical care by different occupational groups are likely to affect their health status directly. In addition, as one of the most important social exchange behaviors, the sense of job security, promotion prospect, prestige, and selffulfillment that workers perceive at work will also have important impacts on their health (Siegrist 1996; Siegrist and Wahrendorf 2016). Accordingly, the following two hypotheses are proposed. 
Hypothesis 3.4: Medical insurance is an important mechanism by which occupation affects health. The medical security provided by employers helps promote individual health.

Hypothesis 3.5: The sense of reward obtained at work is an important mechanism by which occupation affects health. The more rewards individuals receive from work, the better their health.

\section{Data and methods}

\section{Data source}

This study uses data from the 2012 China Labor Force Dynamics Survey (CLDS2012). The sample was drawn from a multistage, stratified, probability sampling design with a selected probability proportional to the size of the labor force. A total of 16,231 individual questionnaires were completed for the working-age population nationwide. The survey divides the respondents into four categories according to their employment status: employer, employee, self-employed, and farmer. Considering the applicability of some core variables, we restrict our analysis to the 4442 employees. After removing missing values and outliers, the analytical sample for this study includes 3940 workers. ${ }^{3}$

\section{Variables and measurement}

This study examines the impact of occupation and working conditions on the health of workers. Our dependent variable is individual health, which is mainly measured by the respondents' self-assessed health. Self-assessed health reflects the overall health status, including personal physical and psychological well-being, as well as relevant selfperceptions and expectations. It is simple and easy to obtain and has strong validity; therefore, it is widely used in social research (Idler and Benyamini 1997). Empirical research on China also shows that self-assessed health exhibits good reliability and validity and is one of the most important indicators reflecting individual health status (Qi 2014). To facilitate analysis, we treat self-assessed health as a binary variable here. Those who answer "very healthy" (22.6\%) and "healthy" (43.2\%) are assigned a value of 1 , and those who answer "fair" (30.2\%), "relatively unhealthy" (3.7\%), and "very unhealthy" $(0.3 \%)$ are assigned a value of $0 .{ }^{4}$

Considering that work-related injuries and occupational diseases are important dimensions of workers' health, this study also investigates self-reported cases of workrelated injuries and occupational diseases to compare and cross-validate key findings with different health measures. The CLDS questionnaire asked whether the respondent had a work-related injury or a disease caused by the occupation. We assign a value of 1 to the answer "Yes" and a value of 0 to the answer "No."

The occupation of the respondent is the core independent variable of this study. We use the International Socio-Economic Index (ISEI) for measuring occupational status (Ganzeboom et al. 1992). The Socio-Economic Index is an effective measure for

${ }^{3}$ CLDS2012 only collected information about working time, job demand and control from the subsample of employees.

${ }^{4}$ In terms of measurement scale, self-assessed health is obviously an ordinal variable. We also tried to fit the corresponding models for ordinal outcome variable, and the results were essentially the same as reported in the text. 
occupational status that provides a comprehensive score for each occupation based on the average education and income of its practitioners (Hauser and Warren 1997).

Considering the salient effect of the work unit on social stratification in Chinese society, we also take it into account when examining the relationship between occupation and health. We distinguish two different types of units. Work units, such as party, government, and military organizations, public institutions, state-owned enterprises, and collective enterprises, are classified as state-owned/collective units and assigned a value of 1 . Other types of units, such as private enterprises, foreign-invested and joint ventures, private industrial and commercial enterprises, are assigned a value of 0 .

In addition to the occupation and work unit, relevant variables related to working conditions examined by this study are respectively measured as follows:

1. Overtime work is measured by the number of hours the respondent worked overtime last month.

2. For working environment and hazard, the questionnaire asks whether the respondent is exposed to a series of harmful factors, including dust, radioactive material, chemical, physical, and biological occupational hazards, at the workplace, and how often he/she wears protective equipment as required at work. Based on this information, we divide respondents into three categories: those who are not exposed to harmful occupational factors, those who are exposed but always or often take protective measures, and those who are exposed but seldom or never take protective measures.

3. The questionnaire measures job demand using the Likert scale, asking whether the respondent needs to engage in a series of physical and cognitive workload in the course of his or her work. The answers are divided into four levels according to frequency: namely, "never," "rarely," "sometimes," and "often." We assign 1 to 4 scores to the above grades, respectively, using a principal component analysis (PCA) with the maximum variance rotation method to retrieve two common factors for job demand: manual labor demand and cognitive labor demand. The two factors account for $48.8 \%$ and $34.1 \%$ of the total variance, respectively.

For the measurement of job control, the questionnaire asks respondents about their decision-making power in terms of work content, work progress, and work intensity. The answers are divided into three levels: "entirely determined by others," "partially determined by self," and "entirely determined by self." We assign the values of the above levels of 1 to 3 in sequence and run a principal component analysis to extract a common factor of job control (the Cronbach's $\alpha$ for the three items is 0.81 ), which explains $72.9 \%$ of the total variance.

4. For occupational medical insurance, the questionnaire asks whether the respondent has medical insurance. This study focuses exclusively on medical resources provided by occupation, so only work-related medical insurance items are considered. All employees who enjoy basic medical care for urban workers, public-funded medical care, unit supplementary medical treatment, and medical assistance for civil servants are all assigned a value of 1 ; otherwise, 0 . 
5. Finally, the questionnaire asks the respondent's subjective evaluation of different dimensions of work. We select six items: income return, job stability, promotion opportunities, the fun of job, respect from others at work, and opportunities to express opinions at work. The corresponding response categories of "very satisfied," "relatively satisfied," "general/not applicable," "somewhat unsatisfied," and "very unsatisfied" are assigned scores of 5 to 1, respectively, and PCA (the Cronbach's $\alpha$ is 0.74 ) is performed to extract one common factor to represent interviewee's subjective perception of occupational rewards.

In addition, we also control other variables that may confound the relationship between occupation and health, including the respondent's age, gender, type of household registration (hukou), and health-related behaviors (smoking and drinking). To better address the independent effect of occupation on health, we also control for the respondent's education and income. Table 1 presents descriptive statistics for the main variables used in this study.

\section{Method}

The statistical analysis of this study includes three steps. First, we examine whether significant differences exist in health status and various working conditions among

Table 1 Descriptive statistics of the main variables $(N=3940)$

\begin{tabular}{lll}
\hline Variable & Mean/proportion & Standard deviation \\
\hline Dependent variable & & - \\
Self-assessed health as "good" & $66 \%$ & - \\
Work-related injury & $8 \%$ & - \\
Occupational disease & $14 \%$ & \\
Independent variable & & 15.23 \\
ISEl & 42.01 & - \\
Type of work unit (state-owned/collective) & $38 \%$ & 26.97 \\
Overtime work (hours/month) & 11.82 & - \\
Exposure to harmful factors at the workplace & $44 \%$ & - \\
Take protective measures against harmful factors & $29 \%$ & 0.99 \\
Manual job demand & -0.01 & 1.00 \\
Cognitive job demand & 0.02 & 1.00 \\
Job control & 0.00 & - \\
Occupational medical insurance & $48 \%$ & 1.00 \\
Perceived job reward & 0.00 & - \\
Control variable & & - \\
Age & $33 \%$ & - \\
Gender (Female) & 3.00 & - \\
Hukou (non-agricultural) & $43 \%$ & - \\
Years of education & $46 \%$ & -1.06 \\
Annual income (10,000 Yuan) & 10.19 & - \\
Smoking & $33 \%$ & \\
Alcohol drinking & & - \\
\hline & & \\
\hline
\end{tabular}


different occupational groups through contingency tables. In the second step, we investigate how occupation affects individual health through working conditions by fitting a series of nested logit regression models for self-assessed health, work-related injury, and self-reported occupational disease. Third, we also aim to estimate to what extent working conditions can explain away the effect of occupation on health, so we use the Karlson-Holm-Breen (KHB) method to decompose the intervening effects of various working conditions (Breen et al. 2013).

Due to the problem of parameter rescaling common in nonlinear models, effect decomposition for nonlinear models is inherently complicated. Considering that $y$ is a binary variable, it is assumed that the underlying continuous latent variable behind it is $y^{*}$. When $y^{*}<0$, we observe $y=0$; otherwise, $y=1$. Assuming that $x$ is the independent variable of interest, $m$ is the intervening variable, and $C$ represents the corresponding control variable. Thus, two models can be fitted separately:

$$
\begin{aligned}
& y^{*}=\alpha_{1}+\beta_{1} x+\gamma_{1} m+\delta_{1} C+\varepsilon_{1} \\
& y^{*}=\alpha_{2}+\beta_{2} x+\delta_{2} C+\varepsilon_{2}
\end{aligned}
$$

Then, the intervening effect of $m$ can be obtained by $\Delta \beta=\beta_{2}-\beta_{1}$. However, since $y^{*}$ is an unobserved latent variable, we cannot directly fit the above models. When fitting the corresponding logit model, the coefficients we obtain are $b_{1}=\frac{\beta_{1}}{\sigma_{1}}$ and $b_{2}=\frac{\beta_{2}}{\sigma_{2}}$, where $\sigma_{1}$ and $\sigma_{2}$ are called scale parameters and are determined by the standard deviation of the model residuals. Since different models have different scale parameters, it is obvious that $b_{2}-b_{1} \neq \beta_{2}-\beta_{1}$.

To overcome this problem, the KHB method proposes that we first use $m$ as the dependent variable and $x$ as the independent variable to fit the model $m=c+d x+r$ and estimate the model's residual $r$. Then, we no longer fit the model (2), but instead consider the following model:

$$
y^{*}=\alpha_{2 *}+\beta_{2 *} x+\gamma_{2 *} r+\delta_{2 *} C+\varepsilon_{2 *}
$$

Since the fits of the model $\left(2^{*}\right)$ and model (1) are the same, $\varepsilon_{1}=\varepsilon_{2^{*}}$. Thus, their corresponding scale parameters $\sigma_{1}$ and $\sigma_{2 *}$ are exactly the same. By model specification, $x$ and $r$ are completely uncorrelated, so $\beta_{2 *}=\beta_{2}$. Therefore, the corresponding logit model satisfies $b_{2 *}-b_{1}=\frac{\beta_{2 *}}{\sigma_{2 *}}-\frac{\beta_{1}}{\sigma_{1}}=\frac{\beta_{2}-\beta_{1}}{\sigma_{1}}$. Based on this result, we can decompose the relative magnitude of the direct and indirect effects of $x$ on $y$.

Table 2 Health status among different occupational status groups (\%)

\begin{tabular}{lllll}
\hline ISEl & Self-assessed health as "good" & Work-related injury & Occupational disease & Sample size \\
\hline Low $(<40)$ & 63.7 & 11.4 & 13.1 & 1975 \\
Medium $(40-64)$ & 67.6 & 6.3 & 11.5 & 1361 \\
High $(\geq 65)$ & 68.7 & 4.0 & 25.3 & 604 \\
Total & 65.8 & 8.5 & 14.4 & 3940 \\
$X^{2}(\mathrm{df}=2)$ & $8.3 *$ & $46.2 * * *$ & $71.0 * * *$ & - \\
\hline$* 00.05 ; * * * p<0.001$ & & &
\end{tabular}




\section{Main findings}

\section{Disparities in health and working conditions by occupation}

To more intuitively show the health disparities among different occupational groups, we first divide the respondents into low (ISEI < 40), medium (ISEI score between 40 and 64), and high occupational status (ISEI score 65 and above). This categorization helps to compare the differences in self-assessed health, work-related injury, and occupational diseases across occupations in a contingency table.

The $\chi^{2}$ test results in Table 2 demonstrate that different occupational groups vary significantly in the selected health indicators. It is worth noting that the patterns of these health indicators among occupational groups are not completely consistent. In terms of self-assessed health, the proportion of people who answered "good" exhibits a positive association with occupational status. The corresponding proportions for the three groups of the low, middle, and high ISEI groups are $63.7 \%, 67.6 \%$, and $68.7 \%$, respectively. The trend of a work-related injury is consistent with self-assessed health. As the ISEI score increases, the incidence of work-related injuries decreases significantly. For instance, the proportion of reporting work-related injury for the low-occupational status group is as high as $11 \%$ but only $4 \%$ for the high-occupational status group. However, no obvious trend is noted among different occupational groups in terms of the occurrence of occupational diseases. In fact, the high-occupational status group reported the highest incidence of occupational disease, with the corresponding percentage being greater than one-quarter $(25.3 \%)^{5}$

Table 3 shows the differences in working conditions across occupational status groups. The results show that different occupational groups exhibit substantial differences in terms of various working conditions, as shown by the corresponding $F$ test or $\chi^{2}$ test. Among them, the amount of overtime work is obviously more prominent in the occupation group with a lower ISEI score. As the ISEI score increases, the manual job demand shows a monotonous decline, while the cognitive job demand shows a monotonous increase. Among groups with higher occupational status, job control, namely, work autonomy, is significantly increased. In general, as occupational status increases, the proportion of people exposed to hazardous materials at the workplace exhibits a downward trend, ${ }^{6}$ while the proportion of people enjoying medical insurance and the sense of job rewards increase rapidly. These results indicate that health disparities between different occupational groups are likely to be related to differences in the nature of work and resultant working conditions. ${ }^{7}$

\footnotetext{
${ }^{5}$ There may be large group heterogeneity in the understanding of occupational disease itself. Further analysis of the CLDS data reveals a large difference between the occupational disease reported by the respondents and those identified by the health department. In our analytical sample, a total of 567 respondents selfreported "occupational diseases." Of these, only 12 cases applied for formal identification, and merely four cases were officially confirmed. Many people with high occupational status may attribute pharyngitis, cervical spondylosis, and stomach disease to "occupational diseases." This is obviously not to be confused with the official statistics of occupational diseases, such as pneumoconiosis and various acute and chronic poisonings. ${ }^{6}$ In terms of the exposure to occupational hazards, the proportion in the high ISEI group is increased compared with that of the medium ISEI group. However, the proportion of working without protective measures in the high ISEI group is only 6.6\%, while the corresponding number in the middle ISEI group is $7.5 \%$.

${ }^{7} \mathrm{We}$ also analyzed the relationship between occupational status and working condition variables through the multiple regression model to control for possible covariates and found that the ISEI score had a significant effect on all working condition variables even after controlling for age, gender, education, and income. These results are available from the authors.
} 
Table 3 Working conditions among different occupational status groups

\begin{tabular}{|c|c|c|c|c|c|c|c|c|}
\hline ISEI & $\begin{array}{l}\text { Overtime } \\
\text { work } \\
\text { (h/month) }\end{array}$ & $\begin{array}{l}\text { Manual } \\
\text { job } \\
\text { demand }\end{array}$ & $\begin{array}{l}\text { Cognitive } \\
\text { job } \\
\text { demand }\end{array}$ & $\begin{array}{l}\text { Job } \\
\text { control }\end{array}$ & $\begin{array}{l}\text { Exposure to } \\
\text { occupational } \\
\text { hazards (\%) }\end{array}$ & $\begin{array}{l}\text { Having } \\
\text { medical } \\
\text { insurance } \\
(\%)\end{array}$ & $\begin{array}{l}\text { Perceived } \\
\text { job rewards }\end{array}$ & $\begin{array}{l}\text { Sample } \\
\text { size }\end{array}$ \\
\hline Low $(<40)$ & 13.6 & 0.3 & -0.3 & -0.1 & 56.4 & 30.5 & -0.2 & 1975 \\
\hline $\begin{array}{l}\text { Medium } \\
(40-64)\end{array}$ & 10.5 & 0.2 & 0.2 & 0.1 & 28.6 & 58.5 & 0.1 & 1361 \\
\hline High ( $\geq 65)$ & 9.0 & -0.6 & 0.7 & 0.2 & 41.4 & 81.3 & 0.3 & 604 \\
\hline Total & 11.8 & 0.0 & 0.0 & 0.0 & 44.5 & 47.9 & 0.0 & 3940 \\
\hline $\begin{array}{l}\text { Test result } \\
(\mathrm{df}=2)\end{array}$ & $9.0 * * *$ & 283. $6 * * *$ & $342.3 * * *$ & $30.2 * * *$ & $333.7 * * *$ & $571.1 * * *$ & $57.7 * * *$ & - \\
\hline
\end{tabular}

The impact of occupation on self-assessed health and the decomposition of its effect

After describing substantial variations in health and working conditions between different occupational groups, in this section, we fit a series of nested logit models on self-assessed health to examine the specific mechanisms through which occupational status affects health. Among them, model 1a is a baseline model that examines the overall health differences by occupational status after controlling for only age and gender composition. Model $2 \mathrm{a}$ adds the type of work unit and its interaction with occupational status in the baseline model to test whether there is a moderating effect of the work unit on the relationship between occupational status and self-assessed health. Model 3a further controls for other possible confounding variables, including hukou status, education, income, and healthrelated behaviors, such as smoking and drinking, to assess the robustness of the key findings. Models 4a to $6 \mathrm{a}$ include three sets of working condition variables to examine the mediating effects of these various dimensions of working conditions on the occupationhealth relationship. Finally, model 7a simultaneously incorporates all working conditions variables and comprehensively examines the specific mechanisms by which occupational status affects self-assessed health. The results of these models are shown in Table 4.

The results in model 1a demonstrate that after controlling for age and gender, occupational status has a significant positive effect on self-assessed health. This result is consistent with our hypothesis 1, namely, the higher the occupational status, the greater the probability of reporting good self-assessed health. According to the fitted coefficients, for each additional ten units of the occupational status score (ISEI), the odds that a respondent reports good self-assessed health increases by approximately $6 \%\left(=\mathrm{e}^{0.006 \times 10}-1\right)$. Moreover, consistent with previous findings, self-assessed health deteriorates with age, and women's self-assessed health is significantly lower than men's self-assessed health.

Model 2a adds the type of work unit and its interaction with occupational status in the model. The results reveal a certain interaction between occupational status and the type of work unit, but it is only significant $(p=0.08)$ at the statistical level of $p<0.1$. According to this effect, in nonstate-owned and collective units, for each additional 10 points in occupational status scores, the odds that respondents report good selfassessed health increases by approximately $13 \%\left(=\mathrm{e}^{0.012 \times 10}-1\right)$. By contrast, in state-

\footnotetext{
${ }^{8} \mathrm{We}$ also tried to control for more factors, such as regional and industrial characteristics. The corresponding results are essentially the same; hence, they are not reported here.
} 
Table 4 Logit models of occupational status and working conditions on self-assessed health $(N=3940)$

\begin{tabular}{|c|c|c|c|c|c|c|c|}
\hline Variables & Model 1a & Model 2a & Model 3a & Model 4a & Model 5a & Model 6a & Model 7a \\
\hline Age & $-0.050 *$ & $-0.045 *$ & $-0.048 *$ & $-0.046 *$ & $-0.043 *$ & $-0.037+$ & $-0.036+$ \\
\hline Age squared/100 & 0.011 & 0.007 & 0.016 & 0.010 & 0.010 & -0.003 & -0.007 \\
\hline Female & $-0.215 * *$ & $-0.219 * *$ & -0.039 & -0.080 & -0.071 & -0.072 & -0.105 \\
\hline ISEI & $0.006 * *$ & $0.012 * *$ & $0.008 *$ & 0.005 & 0.006 & 0.005 & 0.003 \\
\hline $\begin{array}{l}\text { State-owned/collective } \\
\text { unit }\end{array}$ & & 0.295 & 0.272 & 0.176 & 0.240 & 0.293 & 0.203 \\
\hline $\begin{array}{l}\text { State-owned/collective } \\
\text { unit * ISEI }\end{array}$ & & $-0.009+$ & $-0.008+$ & -0.006 & -0.007 & $-0.009+$ & -0.007 \\
\hline Non-agricultural hukou & & & $-0.260 * *$ & $-0.278 * *$ & $-0.260 * *$ & $-0.268 * *$ & $-0.286 * *$ \\
\hline Alcohol drinking & & & 0.094 & 0.094 & 0.090 & 0.106 & 0.105 \\
\hline Smoking & & & 0.056 & 0.069 & 0.060 & 0.061 & 0.073 \\
\hline Years of education & & & $0.023 *$ & $0.022+$ & $0.021+$ & 0.018 & 0.018 \\
\hline Income (logarithmic) & & & $0.303 * * *$ & $0.319 * * *$ & $0.285 * * *$ & $0.213 * *$ & $0.226 * *$ \\
\hline $\begin{array}{l}\text { Overtime working } \\
\text { hours }\end{array}$ & & & & $-0.003 *$ & & & $-0.003 *$ \\
\hline \multicolumn{8}{|c|}{ Working environment (reference group: No exposure to occupational hazards) } \\
\hline $\begin{array}{l}\text { Contact but } \\
\text { protected }\end{array}$ & & & & $-0.228 *$ & & & -0.136 \\
\hline $\begin{array}{l}\text { Contact but NOT } \\
\text { protected }\end{array}$ & & & & $\overline{0.309 * * *}$ & & & $-0.226 * *$ \\
\hline Manual job demand & & & & & $-0.082 *$ & & -0.007 \\
\hline $\begin{array}{l}\text { Cognitive job } \\
\text { demand }\end{array}$ & & & & & -0.008 & & -0.020 \\
\hline Job control & & & & & $0.066+$ & & 0.028 \\
\hline $\begin{array}{l}\text { Occupational medical } \\
\text { insurance }\end{array}$ & & & & & & 0.092 & 0.114 \\
\hline Perceived job reward & & & & & & $0.328 * * *$ & $0.305 * * *$ \\
\hline Intercept & $2.273 * * *$ & $1.967 * * *$ & $1.494 * * *$ & $1.778 * * *$ & $1.550 * * *$ & $1.642 * * *$ & $1.839 * * *$ \\
\hline Log likelihood (df) & $\begin{array}{l}-2437.8 \\
(4)\end{array}$ & $\begin{array}{l}-2435.7 \\
(6)\end{array}$ & $\begin{array}{l}-2421.7 \\
(11)\end{array}$ & $\begin{array}{l}-2410.0 \\
(14)\end{array}$ & $\begin{array}{l}-2417.2 \\
(14)\end{array}$ & $\begin{array}{l}-2380.6 \\
(13)\end{array}$ & $\begin{array}{l}-2373.7 \\
(19)\end{array}$ \\
\hline
\end{tabular}

${ }^{+} p<0.1 ; * p<0.05 ; * * p<0.001 ; * * * p<0.001$

owned/collective units, for the same increase of occupational status scores, the odds of reporting good self-assessed health only increases by $3 \%\left(=\mathrm{e}^{(0.012-0.09) \times 10}-1\right)$. These patterns are largely consistent with our second hypothesis.

Considering that the relationship between occupational status and health may be confounded by variables, such as education, income, hukou, and health-related behaviors, we further include these variables as covariates to assess the robustness of the above findings. ${ }^{8}$ The results of model 3a show that after controlling for these possible confounders, the relationship among occupational status, work unit, and self-assessed health remains consistent with model 2a. As shown in Fig. 1, in state-owned/collective units, with the increase of occupational status, the predicted probability of reporting good self-assessed health arises at a very slow pace. In contrast, in nonstate-owned/collective units, the probability of good self-assessed health increases rapidly as occupational status scores increase. This pattern is also consistent with what is known about the division of income in existing studies. In state-owned/collective units, the income 


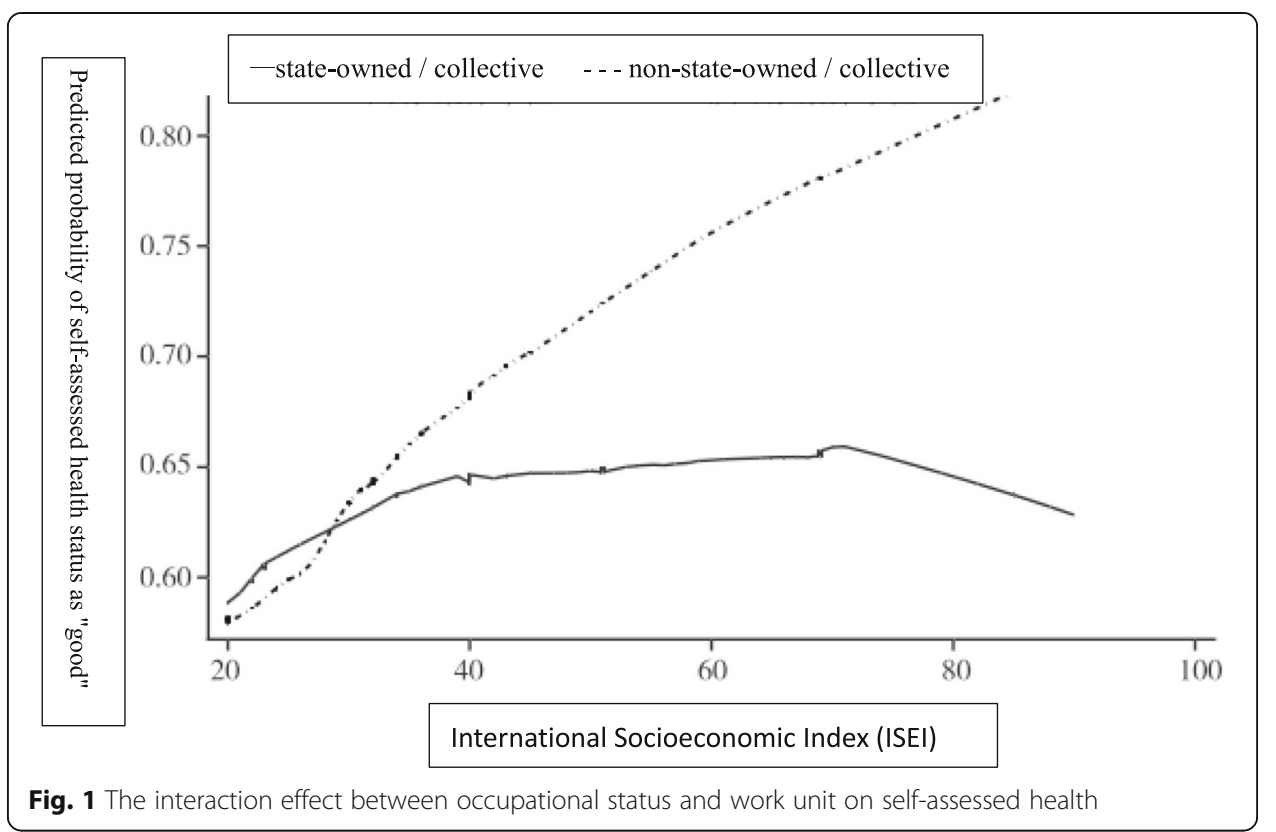

distribution among employees within the unit is relatively even, while the income gap is more manifested between different types of work units (Wang and Wang 2005).

In addition, the results of model $3 \mathrm{a}$ also show that the self-assessed health of nonagricultural hukou holders is significantly lower than that of agricultural hukou; both education and income have a significant promoting effect on self-assessed health. The greater the number of years of education, the higher the individual income, and the more likely that respondents report good self-assessed health. After controlling for the above factors, the effects of gender and smoking and drinking on self-assessed health are no longer significant.

Next, we further examine the mechanism by which occupational status affects selfassessed health. To test hypothesis 3 , model 4 a to model 6 a include variables reflecting various dimensions of working conditions. Comparing the results of these models with model 3a, it can be seen that after adding corresponding indicators of working conditions, the regression coefficient of occupational status is no longer significant, implying that the impact of occupational status on individual self-assessed health mainly occurs through working conditions. This finding provides empirical support for hypothesis 3 . In the process through which occupation impacts individual health, working conditions serve as an important mediating mechanism. Specifically, model 4a shows that selfassessed health significantly deteriorates as overtime work hours increases. Regarding a per hour increase of the average monthly overtime work, the odds that a respondent reports good self-assessed health is reduced by approximately $0.3 \%\left(=1-\mathrm{e}^{-0.03}\right)$, indicating that overtime work has a significant negative impact on individual health. This finding verifies our hypothesis 3.1. In addition, compared with those who are not exposed to any occupational hazards, the odds of reporting good health for those who are in contact but actively take protection decreases by approximately $20 \%\left(=1-\mathrm{e}^{-0.228}\right)$. For those who seldom take protective measures, the odds are reduced by approximately $27 \%$ $\left(=1-\mathrm{e}^{-0.309}\right)$. These results are consistent with our hypothesis 3.2 . 
Our hypothesis 3.3 (job demand and control) is only partially supported in the model. The results of model $5 \mathrm{a}$ show that job control has a role in promoting self-assessed health $(p<0.1)$. For each additional unit increase of the job control score, the odds of reporting good health increases by $7 \%\left(=e^{0.066}-1\right)$. In contrast, intensive manual job demand has a significant negative impact on self-assessed health, while the effect of cognitive job demand is not statistically significant. Specifically, the unit increase in the manual job demand score is associated with a decline of approximately $8 \%$ for the odds of reporting good self-assessed health.

Model 6a incorporates work-related medical insurance and perceived job rewards into the picture. The results show that after controlling for other factors in the model, occupational medical insurance has no significant effect on self-assessed health, which is contradictory to our proposed hypothesis 3.4. However, perceived job rewards are an important factor affecting the worker's self-assessed health. For each unit increase in the job reward score, the odds of which respondents report good self-assessed health substantially increases by $39 \%\left(=\mathrm{e}^{0.328}-1\right)$. Therefore, hypothesis 3.5 is supported by these data.

Finally, model $7 \mathrm{a}$ incorporates all variables of working conditions simultaneously. Compared with previous findings, the corresponding effects of overtime working, working environment, and job reward scores remain statistically significant, while the effects of variables measuring job demand and control are no longer significant. The reason is probably related to the imprecise measurement in this study. For example, the conception of job demand in the "job demand-control" model includes multiple dimensions of workload, intensity, tension, and conflict (Karasek 1979). However, due to data limitations, the focus of this study is restricted to workload and intensity, which may not completely capture the impact of job demand on health.

To assess the relative contribution of the intervening effects of working conditions to the occupation-health link, we use the KHB method to decompose the effects of various variables of working conditions. Table 5 shows the corresponding results. First, based on model 3a, we add each working condition variable separately to examine the proportion of the occupational effect that it can explain. We then include all the intervening variables simultaneously (i.e., model $7 \mathrm{a}$ ) to calculate the proportion of their relative contribution. The results of the KHB decomposition show that for each intervening

Table 5 KHB decomposition for the occupational effect on self-assessed health

\begin{tabular}{lllll}
\hline Variable & $\begin{array}{l}\text { ISEl coefficient } \\
\text { Initial value }\end{array}$ & $\begin{array}{l}\text { ISEl coefficient } \\
\text { Adjusted value }\end{array}$ & $\begin{array}{l}\text { Explained proportion } \\
\text { alone (\%) }\end{array}$ & $\begin{array}{l}\text { Explained proportion } \\
\text { jointly (\%) }\end{array}$ \\
\hline Overall model (model 7a) & 0.008 & 0.003 & - & 56.8 \\
Overtime working hours & 0.008 & 0.007 & 7.4 & 5.7 \\
Working environment & 0.008 & 0.006 & 24.3 & 15.3 \\
Contact but protected & - & - & 12.4 & 6.9 \\
Contact but NOT protected & - & - & 11.9 & 8.4 \\
Manual job demand & 0.008 & 0.006 & 22.8 & 1.9 \\
Cognitive job demand & 0.008 & 0.008 & -4.7 & -4.3 \\
Job control & 0.008 & 0.007 & 10.4 & 4.2 \\
Occupational medical insurance & 0.008 & 0.008 & 3.1 & 4.5 \\
Perceived job reward & 0.008 & 0.006 & 31.0 & 30.0 \\
\hline
\end{tabular}


variable alone, the perceived job reward can explain $31 \%$ of the occupational effect on self-assessed health, the working environment can explain approximately $24 \%$, and the manual job demand can explain approximately $23 \%$. In addition, job control can also explain $10 \%$ of the corresponding effect, and overtime work accounts for approximately $7 \%$.

When all working condition variables are included in the model (model 7a), these variables account for a total of $56.8 \%$ of the occupational effect on self-assessed health. Due to covariations among the working condition variables themselves, the explanatory power of each variable changes to a certain extent. In particular, the explained proportions of manual job demand and job control are reduced substantially. Among all the working conditions considered here, the relative contribution to the occupation-health relationship in the overall model occurs in the following order: job reward (30\%), work environment hazards (15\%), and overtime work hours (6\%).

\section{The impact of occupation on work-related injuries and self-reported occupational} diseases

Considering the multidimensionality of the concept of health and the complexity of its measurement, we further use two additional specific health indicators, namely workrelated injury and self-reported occupational disease, to compare and verify the above findings.

Table 6 Logit models of occupational status and working conditions on work-related injuries $(N=$ 3940)

\begin{tabular}{|c|c|c|c|c|}
\hline Variable & Model 1b & Model 2b & Model 3b & Model 4b \\
\hline Age & 0.029 & 0.027 & 0.031 & 0.005 \\
\hline Age squared/100 & -0.039 & -0.037 & -0.048 & -0.008 \\
\hline Female & $-1.103 * * *$ & $-1.100 * * *$ & $-1.005 * * *$ & $-0.818 * * *$ \\
\hline ISEl & $-0.026 * * *$ & $-0.026 * * *$ & $-0.015 *$ & -0.007 \\
\hline State-owned/collective unit & & 0.183 & 0.588 & 0.612 \\
\hline State-owned/collective unit * ISEI & & -0.003 & -0.006 & -0.008 \\
\hline Non-agricultural hukou & & & $-0.363 *$ & $-0.371 *$ \\
\hline Alcohol drinking & & & -0.036 & -0.081 \\
\hline Smoking & & & 0.157 & 0.143 \\
\hline Years of education & & & $-0.061 * * *$ & $-0.056 * * *$ \\
\hline Income (logarithmic) & & & 0.182 & 0.179 \\
\hline Overtime working hours & & & & -0.001 \\
\hline \multicolumn{5}{|c|}{ Working environment (reference group: No exposure to occupational hazards) } \\
\hline Contact but protected & & & & $-0.700 * * *$ \\
\hline Contact but NOT protected & & & & $0.384 * *$ \\
\hline Manual job demand & & & & $0.290 * * *$ \\
\hline Cognitive job demand & & & & $0.144 *$ \\
\hline Job control & & & & $0.153 *$ \\
\hline Occupational medical insurance & & & & 0.160 \\
\hline Perceived job reward & & & & $-0.198 * *$ \\
\hline Intercept & $-1.472 *$ & $-1.469 *$ & $-1.516 *$ & $-1.993 *$ \\
\hline Log likelihood (df) & $-1084.9(4)$ & $-1084.7(6)$ & $-1071.3(11)$ & $-1030.7(19)$ \\
\hline
\end{tabular}

$* p<0.05 ; * * p<0.001 ; * * * p<0.001$ 
Table 6 shows the impact of occupational status and working conditions on workrelated injuries. According to the results of model $1 \mathrm{~b}$, consistent with what is reported for self-assessed health, workers with higher occupational status face lower risks of work-related injuries. However, unlike previous results, the interaction between occupational status and the type of work unit is not significant (see model 2b). Moreover, after controlling for other variables in the model, women are significantly less likely to have work-related injuries than men, and people with non-agricultural hukou are less likely to have work-related injuries than those with agricultural hukou. In addition, the longer the length of education, the lower the likelihood of work-related injury (see model 3b). These patterns are closely related to the nature and degree of danger of the jobs undertaken by different social groups.

The results of model $4 \mathrm{~b}$ demonstrate that after including variables of working conditions, the effects of occupational status and work unit on work-related injuries are no longer significant. Thus, differences in working conditions explain away the impact of occupation on work-related injuries to a considerable extent. Specifically, working environment hazards, high job demand (especially manual demand), and low perceived job rewards are important risk factors that cause work-related injuries. Surprisingly, according to the model results, workers with high job control are significantly more likely to have experienced an injury, which may result from a reverse causal mechanism. That is, some people are unable to engage in routine labor after suffering from work-related injuries and thus are shifted to relatively low-rank management positions. ${ }^{9}$

KHB effect decomposition results show that the variables of working conditions together explain $47.2 \%$ of the total effect of occupational status on work-related injuries. Among them, relatively large contributors are manual job demand, work environment and occupational hazard, cognitive job demand, job control, and perceived job rewards.

Table 7 shows the model results for self-reported occupational diseases. As mentioned above, the nature and severity of occupational diseases faced by different jobs may vary greatly, so these results should be taken with some caution. The results of model 1c indicate that after controlling for age and gender, the higher the occupational status, the greater the possibility of self-reported occupational diseases; this outcome is in contradiction to the above findings for self-assessed health and work-related injuries. According to the results of model 3c, the relationship between occupational status and the occurrence of the occupational disease varies across different types of work units. Although the incidence of occupational diseases reported by workers in state-owned/ collective units is lower, the positive relationship between occupational status and occupational diseases is also significantly increased. In other words, people with high occupational status in state-owned or collective units are more likely to report occupational diseases. After controlling for other variables in the model, the occurrence of occupational diseases showed an obvious quadratic trend with age that increases initially and then declines. People with non-agricultural hukou are more likely to have

\footnotetext{
${ }^{9}$ Through further examination of the CLDS occupational subcategories, we found that the percentage of selfreported work-related injury (approximately 21\%) in the group of manual supervisors is considerably increased compared with ordinary workers, and the job control score for this group is also relatively high. This finding suggests that in some manual occupations, people who have experienced work-related injuries are assigned to some management tasks with relatively low workload.
} 
Table 7 Logit models of occupational status and working conditions on self-reported occupational diseases $(N=3940)$

\begin{tabular}{|c|c|c|c|c|}
\hline Variables & Model 1c & Model 2c & Model 3c & Model 4c \\
\hline Age & $0.198 * * *$ & $0.181 * * *$ & $0.161 * * *$ & $0.134 * * *$ \\
\hline Age squared/100 & $-0.259 * * *$ & $-0.243 * * *$ & $-0.214 * * *$ & $-0.165 * * *$ \\
\hline Female & -0.019 & -0.007 & 0.053 & $0.250+$ \\
\hline ISEl & $0.018 * * *$ & $0.010 *$ & -0.001 & 0.004 \\
\hline State-owned/collective unit & & -0.012 & -0.478 & -0.307 \\
\hline State-owned/collective unit * ISEI & & 0.008 & $0.013 *$ & 0.008 \\
\hline Non-agricultural hukou & & & $0.343 * *$ & $0.378 * *$ \\
\hline Alcohol drinking & & & -0.002 & -0.031 \\
\hline Smoking & & & 0.034 & -0.054 \\
\hline Years of education & & & $0.034 *$ & $0.037 *$ \\
\hline Income (logarithmic) & & & 0.149 & 0.162 \\
\hline Overtime working hours & & & & 0.002 \\
\hline \multicolumn{5}{|c|}{ Working environment (reference group: No exposure to occupational hazards) } \\
\hline Contact but protected & & & & $0.872 * * *$ \\
\hline Contact but not protected & & & & $0.883 * * *$ \\
\hline Manual job demand & & & & $0.129 *$ \\
\hline Cognitive job demand & & & & $0.316 * * *$ \\
\hline Job control & & & & $0.093+$ \\
\hline Occupational medical insurance & & & & 0.062 \\
\hline Perceived job reward & & & & $-0.307 * * *$ \\
\hline Intercept & $-6.075 * * *$ & $-5.497 * * *$ & $-5.399 * * *$ & $-6.038 * * *$ \\
\hline Log likelihood (df) & $-1579.7(4)$ & $-1573.4(6)$ & $-1559.8(11)$ & $-1461.8(19)$ \\
\hline
\end{tabular}

occupational diseases than those with agricultural hukou. The more years of education, the greater the possibility of reporting occupational diseases.

In addition, model $4 \mathrm{c}$ shows that after adding working conditions variables into the model, the effects of occupational status and work unit are no longer significant. Specifically, hazardous working environments, high manual or cognitive job demand, and low job rewards all lead to an increased risk of occupational diseases. KHB decomposition results show that these variables of working conditions explain away approximately $40 \%$ of the total effect of occupational status on self-reported occupational diseases. Among them, working environment hazards, manual job demand, and cognitive job demand are leading contributors.

\section{Conclusion and discussion}

This study examines the relationship between occupational status and worker's health in contemporary China. We first compared the differences in health and working conditions among various occupational groups and then used logit models and KHB decomposition to explore the specific pathways through which occupation affects health. The main findings from our study are as follows.

First, different occupational groups differ significantly in various health indicators, including self-assessed health, work-related injuries, and self-reported occupational diseases. With the promotion of occupational status, the possibility of reporting good self- 
assessed health increases significantly, while the possibility of suffering work-related injury is greatly reduced. This finding is consistent with the health stratification of socioeconomic status prevailing in many societies. Even after controlling for possible confounding variables, such as hukou, education, and income, occupational status still exhibits a significant independent effect on health.

Second, different occupational groups vary substantially in terms of working conditions, and the impact of occupational status on health is largely accounted for by differences in working conditions. This notion exemplifies occupational differentiation as a macrostructural force that restricts the working space of various occupational groups through the allocation of a series of relevant risks and resources, shapes the working conditions faced by laborers, and causes health consequences. According to the KHB decomposition results, working conditions account for approximately half of the total effect of occupational status on health. Taken together, occupational hazards in the working environment, high-intensity workloads (especially high physical demand), and perceived rewards from work are the most important pathways by which occupational status affects health.

This finding shows that occupation, as the core of modern social activities, acts on the health of workers through multiple mechanisms. On the one hand, in contrast to relatively mature Western societies, the working environment and occupational safety in China still seriously threaten the health of workers due to the impact of rapid industrialization and social transformation. On the other hand, the "job demand-control" model and the "effort-reward imbalance" theory also receive considerable empirical support in this study. Nevertheless, compared with empirical findings from other countries indicating that the impact of job control on occupational health is prominent (Marmot et al. 1997), the high demand for manual work in China still results in the impaired health of workers and frequent work-related injuries. This finding may be related to China's existing economic structure and stage of development. In addition, occupation, which usually requires a significant labor effort, must be properly rewarded to maintain the socio-psychological balance of individuals. Of course, this reward does not merely refer to material compensation but also includes safety, job security, the degree of respect, promotion opportunities, and even a sense of selfrealization. With the upgrading and transformation of China's industrial structure, the relative importance of this socio-psychological mechanism through which occupation affects health is expected to increase further.

Third, the results for self-assessed health show that the impact of occupational status on the health of workers is moderated to a certain extent by the nature of the work unit. Our study found that compared with the state-owned/collective sector, the effect of occupational status on workers' self-assessed health is significantly stronger in the nonstate-owned/collective sector. Thus, as an important element in Chinese social stratification, the division of work unit also permeates the role of occupational status in worker's health. In the state-owned and collective sectors, work units have exerted a certain restraining effect on health differentiation between different occupational groups and help to maintain a relatively equal health status within the sector.

By contrast, in nonstate-owned sectors, the occupational division of worker's health is much larger, which is consistent with existing findings (Su et al. 2000; Zhang et al. 2010). Therefore, to promote the health of laborers in Chinese society, it is especially important to pay close attention to the rights of laborers in private and small-scale enterprises. 
However, it is worth noting that this moderating role of work unit has not been verified in corresponding analyses of work-related injuries and self-reported occupational diseases.

Finally, unlike self-assessed health and work-related injuries, the occurrence of occupational diseases in different occupational groups does not support the general health gradient. In fact, people with high occupational status reported more incidences of occupational diseases. Previous studies have paid more attention to the disease burden on the bottom spectrum of occupational stratification, but the results of this study suggest that the higher occupational groups are also not immune from occupational diseases. All occupational groups may bear the burden of health losses from high-intensity labors, but substantial heterogeneity exists in the types of risks in different jobs. Therefore, in addition to preventing fatal occupational diseases, such as pneumoconiosis and poisoning faced by manual labor workers, we should also pay attention to the health status of other occupational groups. Although cervical and lumbar diseases that plague many white-collar groups are not fatal in themselves, they also have serious negative consequences for work efficiency and quality of life. Of course, the nature and severity of different occupational diseases should not be blurred, which also reminds us that it is necessary to improve the current measurement instrument in subsequent investigations to make the results more comparable.

Due to data and other limitations, there are still some drawbacks to this study. First, this study uses cross-sectional data and fails to exclude inverse causality from health to occupation. The relationship between occupation and health shown above may be derived in part from the selective impact of health on occupational attainment. ${ }^{10}$ Second, information about health and working conditions comes from individual self-reports and subjective assessment, which may affect the validity of the measurement to a certain extent. However, previous studies have shown that self-reported working conditions are strongly correlated with the external evaluation from experts (Theorell et al. 1998). Finally, due to the limitation of data availability, the inspection of working conditions is constrained. For instance, the measurement of job demand is only limited to certain aspects, and the theory of "effort-reward imbalance" has not been fully tested. These issues call for more comprehensive investigations in future studies to better understand the complex relationship between occupational stratification and health inequality.

\section{Acknowledgments}

N/A

\section{Authors' contributions}

The first author is responsible for the overall design and writing for this study. The second author made contributions for carrying out preliminary analysis and drafting the manuscript. The third author provided the data, reviewed the full manuscript and is responsible for all data-related issues. The author(s) read and approved the final manuscript.

\section{Funding}

The project was supported by a special program from Renmin University of China for constructing world-class universities and first-class disciplines.

${ }^{10}$ To partially control this selective effect, we excluded those who had changed their occupational types from the sample based on the retrospective job history information in the CLDS and redid the analysis. The results obtained were largely consistent with the results reported in the main text. 
Availability of data and materials

We based our study on the 2012 China Labor-force Dynamics Survey, which is publicly available from the Sun Yat-Sen University.

\section{Competing interests}

The authors declare that they have no competing interest.

\section{Author details}

'Department of Sociology, Renmin University of China, No.59 Zhongguancun Street, Haidian District, Beijing 100872, China. ${ }^{2}$ Tianjin University, Tianjin, China. ${ }^{3}$ School of Sociology and Anthropology, Sun Yat-Sen University, Guangzhou, China.

Received: 25 May 2020 Accepted: 8 July 2020

Published online: 11 August 2020

\section{References}

Adler, N.E., and J.M. Ostrove. 1999. Socioeconomic status and health: what we know and what we don't. Annals of the New York Academy of Sciences 896 (1): 3-15.

Andersen, R., and J.F. Newman. 2005. Societal and individual determinants of medical care utilization in the United States, Milbank Quarterly 83 (4): 1-28.

Breen, R., K.B. Karlson, and A. Holm. 2013. Total, direct, and indirect effects in logit and probit models. Sociological Methods \& Research 42 (2): 164-191.

Chen, F., Y. Yang, and G. Liu. 2010. Social change and socioeconomic disparities in health over the life course in China: a cohort analysis. American Sociological Review 75 (1): 126-150.

Chen, M., and A. Chan. 2010. Occupational health and safety in China: the case of state-managed enterprises. International Journal of Health Services 40 (1): 43-60.

Ganzeboom, H.B., P.M. De Graaf, and D.J. Treiman. 1992. A standard international socio-economic index of occupational status. Social Science Research 21 (1): 1-56.

Hauser, R.M., and J.R. Warren. 1997. Socioeconomic indexes for occupations: a review, update, and critique. Sociological Methodology 27 (1): 177-298.

Hu, Anning. 2014. Can education make us healthier? An urban-rural comparative analysis based on the 2010 Chinese general social survey. Social Sciences in China 5: 116-130.

Idler, E.L., and Y. Benyamini. 1997. Self-rated health and mortality: a review of twenty-seven community studies. Journal of Health and Social Behavior 38 (1): 21-37.

Jiao, Kaishan. 2014. Research on the influencing factors of health inequality. Sociological Studies 5: 24-46.

Karasek, R. 1979. Job demands, job decision latitude, and mental strain: implications for job redesign. Administrative Science Quarterly 24: 285-308.

Kristensen, T.S. 1995. The demand-control-support model: methodological challenges for future research. Stress Medicine 11 (1): $17-26$.

Kristensen, T.S., V. Borg, and H. Hannerz. 2002. Socioeconomic status and psychosocial work environment: results from a Danish national study. Scandinavian Journal of Public Health 30: 41-48.

LaDou, J. 2003. International occupational health. International Journal of Hygiene and Environmental Health 206 (4): 303-313.

Landsbergis, P.A. 2010. Assessing the contribution of working conditions to socioeconomic disparities in health: a commentary. American Journal of Industrial Medicine 53: 95-103.

Leigh, J., P. Macaskill, E. Kuosma, and J. Mandryk. 1999. Global burden of disease and injury due to occupational factors. Epidemiology 10 (5): 626-631.

Leonard, C., N. Fanning, J. Attwood, and M. Buckley. 1998. The effect of fatigue, sleep deprivation and onerous working hours on the physical and mental well-being of pre-registration house officers. Irish Journal of Medical Science 167 (1): 22-25.

Li, Hanlin. 2007. Integration and control in a transitional society—on the changes of China's work unit system. Jilin University Journal Social Sciences Edition 4: 46-55.

Li, Lulu, Dalei Miao, and Xiuxiao Wang. 2009. Market transformation and changes in work unit: re-discussion on studies of work unit. Chinese Journal of Sociology 4: 1-25.

Li, Lulu, Guangqiang Qin, and Jianwei Chen. 2012. Construction of an authoritative stratum system: an analysis based on working condition and organizational authority. Sociological Studies 2: 46-76.

Liu, Linping, Guanghuai Zheng, and Zhongwei Sun. 2011. Labor rights and mental health: based on a questionnaire survey of migrant workers in the Yangtze River Delta and Pearl River Delta Areas. Sociological Studies 4: 164-184.

Marmot, M.G. 2004. The status syndrome: how social standing affects our health and longevity. New York: A Holt Paperback.

Marmot, M.G., H. Bosma, H. Hemingway, E. Brunner, and S. Stansfeld. 1997. Contribution of job control and other risk factors to social variations in coronary heart disease incidence. The Lancet 350: 235-239.

Qi, Liangshu. 2006. Income, income inequality and health: the impact of urban-rural differences and occupational status. Economic Research Journal 11: 16-26.

Qi, Yaqiang. 2014. Reliability and validity of self-rated general health. Chinese Journal of Sociology 6: 196-215.

Qiao, Y., P.R. Taylor, S. Yao, and M.S. Tockman. 1997. Risk factors and early detection of lung cancer in a cohort of Chinese tin miners. Annals of Epidemiology 7 (8): 533-541.

Schrijvers, C., and H.D. van de Mheen. 1998. Socioeconomic inequalities in health in the working population: the contribution of working conditions. International Journal of Epidemiology 27 (6): 1011-1018.

Siegrist, J. 1996. Adverse health effects of high effort/low reward conditions. Journal of Occupational Psychology 1 (1): 27-41.

Siegrist, J., and M. Wahrendorf. 2016. Work stress and health in a globalized economy: the model of effort-reward imbalance. Switzerland: Springer.

Sokejima, S., and S. Kagamimori. 1998. Working hours as a risk factor for acute myocardial infarction in Japan: case-contro study. British Medical Journal 317 (7161): 775-780. 
Su, Z., S. Wang, and S.P. Levine. 2000. National occupational health service policies and program for workers in small-scale industries in China. American Industrial Hygiene Association 61 (6): 302-308.

Theorell, T., A. Tsutsumi, and J. Hallquist. 1998. Decision latitude, job strain, and myocardial infarction: a study of working men in Stockholm. American Journal of Public Health 88 (3): 382-388.

Wang, Shaoguang. 2005. State policy orientation, extractive capacity and the equality of healthcare in urban China. Social Sciences in China 6: 101-120.

Wang, Tianfu, and Feng Wang. 2005. Group factors in China's urban income distribution: 1986-1995. Sociological Studies 3: 156-181.

Winkleby, M.A., D.E. Jatulis, E. Frank, and S.P. Fortman. 1992. Socioeconomic status and health: how education, income, and occupation contribute to risk factors for cardiovascular disease. American Journal of Public Health 82 (6): 816-820.

Yu, S., G. Gu, W. Zhou, and S. Wang. 2008. Psychosocial work environment and well-being: a cross-sectional study at a thermal power plant in China. Journal of Occupational Health 50 (2): 155-162.

Yu, S., A. Nakata, G. Gu, N.G. Swanson, and S. Wang. 2013. Job strain, effort-reward imbalance and neck, shoulder and wrist symptoms among Chinese workers. Industrial Health 51: 180-192.

Yu, W., I. Yu, Z. Li, and S. Xie. 2012. Work-related injuries and musculoskeletal disorders among factory workers in a major city of China. Accidental Analysis and Prevention 48: 457-463.

Zhang, X., Z. Wang, and T. Li. 2010. The current status of occupational health in China. Environmental Health and Preventive Medicine 15 (5): 263-270.

\section{Publisher's Note}

Springer Nature remains neutral with regard to jurisdictional claims in published maps and institutional affiliations.

\section{Submit your manuscript to a SpringerOpen ${ }^{\circ}$} journal and benefit from:

- Convenient online submission

- Rigorous peer review

- Open access: articles freely available online

High visibility within the field

- Retaining the copyright to your article 